CCA 4636

\title{
TYROSINE METABOLISM: URINARY EXCRETION STUDIES IN PARKINSONISM
}

\author{
WALTER E. SZPUNAR*, ARTHUR D. ERICSSON** AND DAISY S. McCANN+ \\ *Department of Medicine, Wayne County General Hospital, Eloise, Michigan 48132, **Department \\ of Neurology, Baylor College of Medicine, Houston, Texas 77025 and Department of Medicine, \\ Wayne County General Hospital, Eloise, Michigan $4813^{2}$ and The University of Michigan, Ann \\ Arbor, Michigan 48104 (U.S.A.)
}

(Received April i3, 1971)

\section{SUMMARY}

Vanilmandelic, homogentisic and homovanillic acid excretions were studied in parkinsonian patients on and off L-dopa.

Vanilmandelic acid excretions were quantitated both by gas-chromatographic and colorimetric methods. A marked increase in the excretion of this acid was demonstrated in the parkinsonian patient as compared to controls. Although vanilmandelic excretion rises under the influence of L-dopa, the increase is much smaller than that of free homovanillic acid. The latter consistently accounts for some $18-20 \%$ of the administered L-dopa dose. While vanilmandelic acid excretions even under the influence of L-dopa correlate well with the patients' weight, no such correlation could be obtained with homovanillic acid.

Homogentisic acid could not be detected in urine specimens of patients either on or off L-dopa. No correlation was observed between the clinical status or response to L-dopa of the patients and their excretion of acidic urinary catabolites.

\section{INTRODUCTION}

In conjunction with studies ${ }^{1,2}$ of dopa metabolites in the cerebrospinal fluid of a series of patients with parkinsonism, urinary excretion studies of homovanillic acid (HVA), vanilmandelic acid (VMA) and homogentisic acid (HA) were undertaken.

HVA determinations utilized the method of Sato ${ }^{3}$; for both VMA and HA innovations and/or modifications of current methodologies were required, especially in the samples obtained from patients receiving L-dopa therapy.

No difference was observed between the 24 -h urinary excretion values of HVA

\footnotetext{
* A portion of this work was submitted to the Office for Graduate Studies, Wayne Stale University in partial fulfillment of the requirements for the degree of Doctor of Philosophy.

Reprint requests should be addressed to: D. S. McCann, Ph. D., Department of Medicine, Wayne County General Hospital, Eloise, Michigan 48132.
} 
from parkinsonian patients and normal individuals drawn from the same age group as the patients. HA could not be demonstrated in the urine of any of the patients either before or after initiation of L-dopa therapy. VMA excretion on the other hand was almost doubled in parkinsonian patients as compared to controls. This paper then is concerned with HVA, VMA and HA excretion in parkinsonian patients, on and off L-dopa, as well as the methodologies employed to measure these parameters. In the latter area the comparison of gas-chromatographic and colorimetric data for the determination of VMA is, perhaps, of particular interest.

\section{METHODS}

\section{Urine collection}

Twenty-four-hour urine specimens were obtained from patients and controls in bottles which contained $20 \mathrm{ml}$ of $6 \mathrm{~N} \mathrm{HCl}$ as a preservative. While the collections were being made the bottles were kept on ice, and after the specimens were completed, aliquots were frozen immediately until use. The controls, or non-parkinson urine specimens, were obtained from individuals over 50 years old, since Parkinson's disease most commonly manifests itself in this age group. The completeness of various $24-h$ collections was monitored by creatinine determinations.

\section{HVA determination}

Homovanillic acid was determined by the method of Sato ${ }^{3}$.

\section{Homogentisic acid determination}

The method of Stoner and Blivaiss ${ }^{4}$ was the first used in an attempt to locate HA in dopa urines. It was found that such compounds as 3,4-dihydroxyphenylacetic acid, 3,4-dihydroxyphenylpyruvic acid, norepinephrine, and dopamine produced interfering absorbance readings. Although small amounts of these compounds are of little consequence in quantitating the gram amounts of HA encountered in alcaptonuria, their presence in the dopa urines vitiated any attempt to use the method in the current study.

Six dopa urines were run by an enzymatic assay for $\mathrm{HA}^{5}$ and no HA was detected. However, when a $4-\mu \mathrm{g}$ spike of the acid was added, it was not recovered in 4 of these urines. An additional io $\mu \mathrm{g}$ had to be added before detection occurred. This suggested that levels of less than $3 \mu \mathrm{g} \mathrm{HA} / \mathrm{ml}$ of urine or several $\mathrm{mg} / 24 \mathrm{~h}$ would pass undetected.

Consequently, the following method was developed for the partial purification of urine and subsequent qualitative detection of homogentisic acid. The $\mathrm{pH}$ of the urine was adjusted to 4.0 with $\mathrm{NaOH}$ and $\mathrm{I} 0 \mathrm{ml}$ added to a Dowex $5^{\circ} \mathrm{W}-\mathrm{X}_{4}$ column 50-I00 mesh, $8 \mathrm{~cm} \times \mathrm{I} \mathrm{cm}$ which had previously been washed with I5 $\mathrm{ml} \mathrm{I} N \mathrm{NaOH}$, I5 $\mathrm{ml} \mathrm{H}_{2} \mathrm{O}$, I5 $\mathrm{ml} \mathrm{I} N \mathrm{HCl}$, and $45 \mathrm{ml} \mathrm{H}_{2} \mathrm{O}$. The IO-ml eluate was collected and added to an $\mathrm{AGl}-\mathrm{X}_{4}$ anion column $(4 \mathrm{~cm} \times \mathrm{I} \mathrm{cm})$. The column was then rinsed with $2 \mathrm{ml}$ $50 \%$ methanol, $2 \mathrm{ml} 75 \%$ methanol, and $2 \mathrm{ml} 90 \%$ methanol. Ten $\mathrm{ml}$ of $100 \%$ methanol were added, followed by $9 \mathrm{ml}$ of methanol-acetic acid $(98: 2, \mathrm{v} / \mathrm{v})$. The HA was then eluted from the column with $20 \mathrm{ml}$ of the methanol-acetic acid mixture.

The material was evaporated to dryness at room temperature under vacuum and I $\mathrm{ml}$ of o.or $N \mathrm{HCl}$ added. The HA was extracted from the acid with two I.5-ml portions of ethyl acetate. This ethyl acetate extract was then dried under vacuum at 
room temperature and the residue dissolved in $\mathrm{I} \mathrm{ml}$ methanol, which in turn was evaporated on a water bath $\left(80^{\circ}\right)$ to one or two drops. Homogentisic acid alone and urine samples spiked with Io $\mu \mathrm{g}$ of homogentisic acid were also taken through the procedure.

Chromatographs were developed with benzene-chloroform-acetic acid-water ( $\mathrm{I}: 3: 4: 2$ ) on $0.25-\mathrm{mm}$ silica gel plates (Adsorbosil-I, Applied Science) and with benzene-chloroform-acetic acid-water $(\mathrm{I}: 6: 6: 2)$ and benzene-methanol-acetic acid (45:8:4) on pre-coated silica gel F-254 plates (Merck). Visualization was obtained with phenol reagent (Folin-Ciocalteau, Fisher Scientific) followed by $10 \% \mathrm{Na}_{2} \mathrm{CO}_{3}$. The sensitivity of the method corresponds to a detection of $0.5 \mu \mathrm{g} / \mathrm{ml}$.

\section{$V M A$ colorimetric determination}

The method of Wybenga and Pileggi6 for VMA determination appeared suitable provided certain precautions were observed. Accurate quantitation demands that a series of standards be run together with each series of specimens. The VMA standard solution, made by dissolving $6 \mathrm{mg}$ VMA (Calbiochem, Los Angeles) in roo $\mathrm{ml}$ o.or $N$ $\mathrm{HCl}$, was stable for somewhat less than two weeks, even when stored at $4^{\circ}$. The color reagent addition, removal from ice, and subsequent absorbance readings have to be timed carefully to insure reproducibility. Finally, the reading of the urines and the urine blanks against water was omitted in favor of reading each sample against its own blank.

\section{VMA gas-chromatographic procedure}

Five $\mathrm{ml}$ of urine ( $\mathrm{pH}$ adjusted to $5.5^{-6 . \mathrm{I})}$ mixed with $5 \mathrm{ml}$ of o.I $\mathrm{M}$ phosphate buffer ( $\mathrm{pH}$ 6.I) were passed through a column packed with $\mathrm{AGI}_{\mathrm{I}} \mathrm{X}_{4}$ anion resin ( $6 \mathrm{~cm} \times$ I cm, Bio-Rad Laboratories, California) previously washed with I $N \mathrm{NaOH}$, $\mathrm{H}_{2} \mathrm{O}$, I $N$ acetic acid, and finally with $0.2 \mathrm{M}$ sodium acetate until equilibrium at $\mathrm{pH}$ 6.I was reached. The effluent was discarded and VMA eluted from the column with I $2 \mathrm{ml}$ of $3.0 \mathrm{~N} \mathrm{NaCl}$. The material was then heated in a boiling water bath in order to avoid inhibition of VMA oxidation by other urinary constituents. After the eluate cooled to room temperature, $8 \mathrm{ml}$ of $\mathrm{I} \mathrm{M} \mathrm{K}_{2} \mathrm{CO}_{3}$ were added. VMA standards were taken through the same procedure, which thus far is essentially the same procedure used in the colorimetric determination of VMA.

The eluates were divided into two Io-ml portions, one of which was treated as a blank. To one ro-ml aliquot was added $0.4 \mathrm{ml}$ of $4 \% \mathrm{NaIO}_{4}$. To prevent oxidation, $0.6 \mathrm{ml}$ of $\mathrm{x} 0 \% \mathrm{Na}_{2} \mathrm{~S}_{2} \mathrm{O}_{5}$ was added to the blanks. The solutions were then heated at $50^{\circ}$ for 30 min to oxidize VMA to vanillin. At the end of this period, $\mathrm{Na}_{2} \mathrm{~S}_{2} \mathrm{O}_{5}$ is added to the standards and urine samples and $\mathrm{NaIO}_{4}$ to the blanks.

The $\mathrm{pH}$ was adjusted to $7.5-7.6$ and the vanillin twice extracted with reagent grade $\mathrm{CH}_{2} \mathrm{Cl}_{2}(8 \mathrm{ml}, 8 \mathrm{ml})$. To the organic layer were added $5 \mathrm{~g} \mathrm{Na}_{2} \mathrm{SO}_{4}$ (anhydrous) and the solution mixed and centrifuged. The supernate was dried under $\mathrm{N}_{2}$ to I $\mathrm{ml}$ and $0.040 \mathrm{ml}$ of chlorodifluoroacetic anhydride (K and $\mathrm{K}$ Laboratories, Inc., Plainview, New York) added to both samples and blanks. The solutions were left at room temperature for at least $20 \mathrm{~h}$ after which time they were completely dried under $\mathrm{N}_{2}$. Two $\mathrm{ml}$ of distilled ethyl acetate were added and $\mathrm{I} \mu \mathrm{l}$ thereof injected into a gas chromatograph equipped with an EC detection unit (Hewlett Packard Model 402 with a ${ }^{63} \mathrm{Ni}$ cell). Conditions used for the chromatography were: a $4^{\prime}$ U-shaped column, I.D. $4 \mathrm{~mm}$, 
packed with 80/100 Gas Chrom $Q$ coated with $1 \%$ XE-60; carrier gas, $95 \%$ Argon, $5 \%$ methane at a flow rate of $60 \mathrm{ml} / \mathrm{min}$; oven temperature $\mathrm{I} 20^{\circ}$, flash heater $\mathrm{I} 40^{\circ}$, and $\mathrm{EC}$ detector $280^{\circ}$.

A peak which corresponds to the chlorodifluoroacetic derivative of vanillin appeared at $7 \mathrm{~min}$. When VMA itself is chromatographed, before and after treatment with chlorodifluoroacetic anhydride, no such peak is observed. Nor does underivatized vanillin give a peak of the appropriate retention time. The peak height is proportional to the amount of material injected and such a standard curve obtained from VMA standards taken through the entire procedure is illustrated in Fig. I. Urines spiked with VMA and taken throngh the procedure show a proportional increase in peak

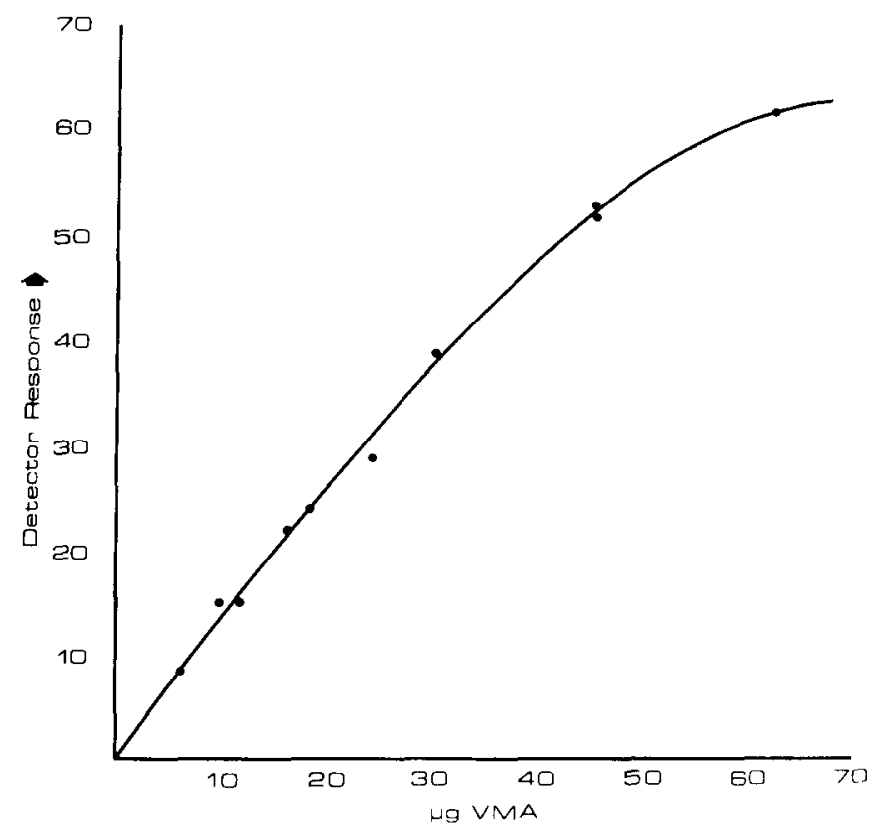

Fig. I. Standard curve for the GLC determination of vanilmandelic acid. Points on this curve correspond to standards taken through the entire analytical procedure described in the text.

height at $7 \mathrm{~min}$ and urines treated as blanks (VMA not oxidized to vanillin) show little or no peaking at the 7 -min retention time. Since the sensitivity of the gas chromatograph is subject to change, standards have to be run with every set of urines. Precision for the gas-chromatographic method is of the order of $3 \%$ if the initial sample contains approximately $30 \mu \mathrm{g}$ of VMA. Accuracy calculated on the recovery of ro- and $24-\mu \mathrm{g}$ quantities of VMA added to the urine samples was of the order of $98 . \mathrm{I} \pm 6.6 \%$.

\section{RESULTS}

HVA

No difference was observed in baseline excretions (i.e., pre-dopa) of HVA as compared to normal controls, which were $4.0 \pm \mathrm{I} .4 \mathrm{mg} / 24 \mathrm{~h}$ and $3.8 \pm \mathrm{I} .7 \mathrm{mg} / 24 \mathrm{~h}$ respectively. As reported by others ${ }^{7,13}$ HVA excretion rose sharply with the dose of 
ingested L-dopa. Approximately $18-20 \%$ of a given dose of the chemotherapeutic agent was recoverable as free HVA in the urine (Table I).

TABLE I

AVERAGE HVA EXCRETION OF L-DOPA PATIENTS

\begin{tabular}{lcc}
\hline $\begin{array}{l}\text { L-Dopa } \\
\text { (grams/day) }\end{array}$ & $\begin{array}{l}\text { Number } \\
\text { tested }\end{array}$ & $\begin{array}{l}\text { HVA average } \\
(m g / 24 h \pm S D)\end{array}$ \\
\hline 0 & I 5 & $4.0 \pm \mathrm{I} .4$ \\
2 & 5 & $427 \pm 223$ \\
4 & 2 & 645 \\
5 & $\mathrm{I} 4$ & $906 \pm 169$ \\
6 & $\mathrm{I} 3$ & $\mathrm{IIO0 \pm 338}$ \\
7.5 & 6 & $\mathrm{I} 40 \mathrm{OI} \pm 374$ \\
\hline
\end{tabular}

\section{$H A$}

As pointed out in the introduction, no HA was recovered from any of the urines tested either pre or post dopa. The methodology was adequate to pick up readily as little as $0.5 \mathrm{mg} \mathrm{HA} / \mathrm{l}$ of urine. This finding was in accord with that of Cotzias ${ }^{8}$ and in contrast to that reported by Arras and Bailey'.

\section{$V M A$}

Both the colorimetric and the gas-chromatographic procedures show an increased VMA excretion in the parkinsonian patient as compared to normals (Table II).

TABLE II

AVERAGE VMA EXCRETION OF CONTROLS AND PARKINSON PATIENTS

\begin{tabular}{|c|c|c|c|}
\hline Subject & Method & $\begin{array}{l}\text { Number } \\
\text { tested }\end{array}$ & $\begin{array}{l}V M A \text { average } \\
(m g / 24 h \pm S D)\end{array}$ \\
\hline Controls* & Colorimetric & IO & $5.4 \pm 1.6$ \\
\hline Parkinsonian* & Colorimetric & 32 & $6.8 \pm 2.4$ \\
\hline Controls $^{+}$ & Colorimetric & 9 & $5.7 \pm 2.2$ \\
\hline Parkinsonıan ${ }^{+}$ & Colorimetric & 6 & $7.3 \pm 2.0$ \\
\hline Controlst & Gas chromatography & 9 & $2.9 \pm \mathbf{1} .6$ \\
\hline Parkinsonian ${ }^{+}$ & Gas chromatography & I I & $5.2 \pm 2.1$ \\
\hline
\end{tabular}

Subjects fell into two groups. Group I urines* were analyzed colorimetrically only. Group II ${ }^{+}$ represents a different group of controls and patients whose urines were analyzed both colorimetrically and by GLC.

The preliminary work was done colorimetrically; with recognition of the fact that gas-chromatographic procedures for urinary VMA ${ }^{10-12}$ in general yield lower values than colorimetric ones, the question arose whether the observed increases $(6.8 \mathrm{mg} / 24 \mathrm{~h}$ for 27 parkinsonian patients as compared to $5.2 \mathrm{mg} / 24 \mathrm{~h}$ for 5 controls ${ }^{13}$ ) were in fact due to VMA or to whatever substance contributes to the color of the spectrophotometric method. The gas-chromatographic procedure which was then devcloped not only confirmed the colorimetric data but sharply accentuated the difference between controls and parkinsonian patients. The implication is that the increase noted in the latter group by the colorimetric method was de facto due to VMA so that on a percentage basis the error incurred by the colorimetric method is much greater for the controls than for the patients. 
TABLE III

AVERAGE VMA EXCRETION OF L-DOPA PATIENTS

\begin{tabular}{lcl}
$\begin{array}{l}\text { L-dopa } \\
\text { (grams/day) }\end{array}$ & $\begin{array}{l}\text { Number } \\
\text { tested }\end{array}$ & $\begin{array}{l}\text { IMA average } \\
(m g / 24 h \pm S D)\end{array}$ \\
\hline 0 & 32 & $6.8 \pm 2.4$ \\
2 & 5 & $14.8 \pm 1.5$ \\
4 & 2 & 19.8 \\
5 & 14 & $22.4 \pm 8.9$ \\
6 & 12 & $25.9 \pm 7.6$ \\
7.5 & 6 & $28.6 \pm 9.1$ \\
\hline
\end{tabular}

Urinary VMA, as did HVA, rose as the L-dopa dose increased (Table III). However the absolute increase is of a far smaller order of magnitude than the HVA increase nor is the percentage of L-dopa converted to VMA constant. Rather one finds that as the dose increases the percent metabolized by this route decreases (Table III).

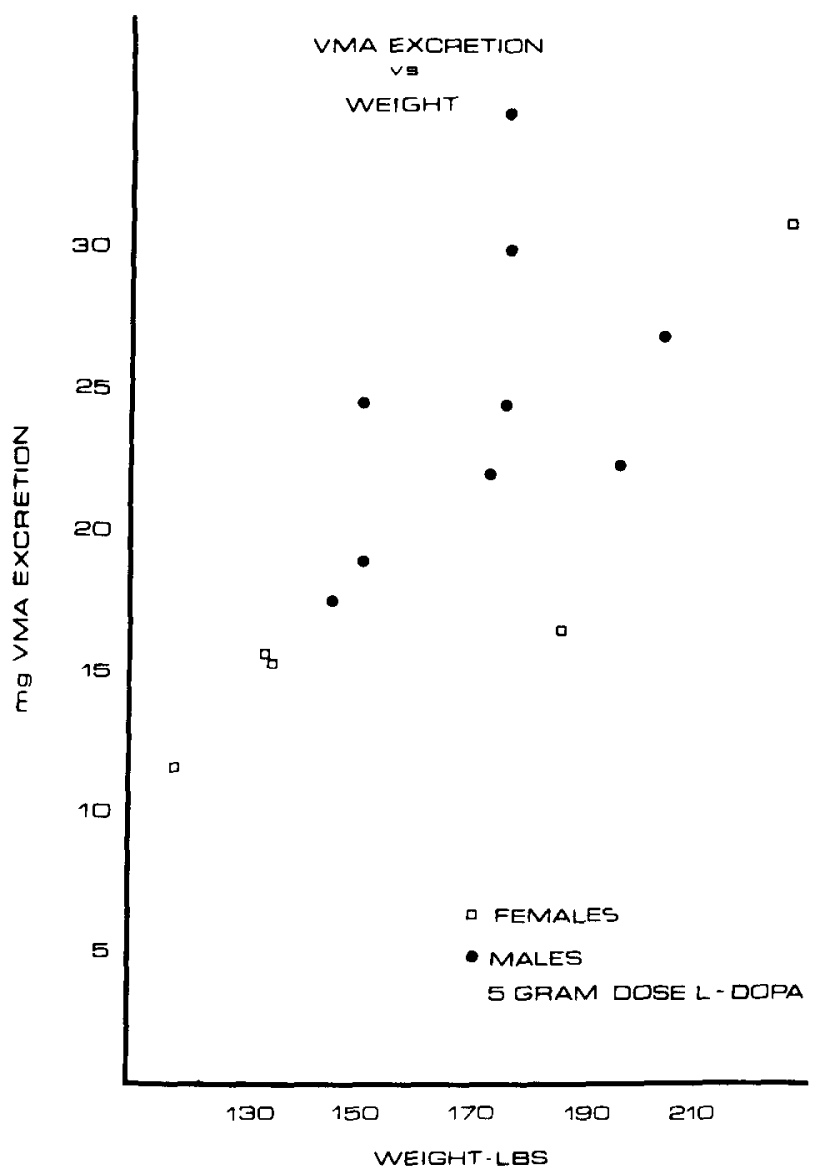

Fig. 2. Twenty-four-hour urinary excretion of vanilmandelic acid $v s$, weight of patients on 5 grams daily dose of L-dopa.

Clin. Chim. Acta, 35 (I97I) 209-2I 7 
Another major difference between the pattern of metabolism of HVA and VMA is that the amount of a given dose of L-dopa metabolized to VMA correlates strikingly with the weight of the patient (Fig. 2), while no such correlation exists for HVA (Fig. 3).

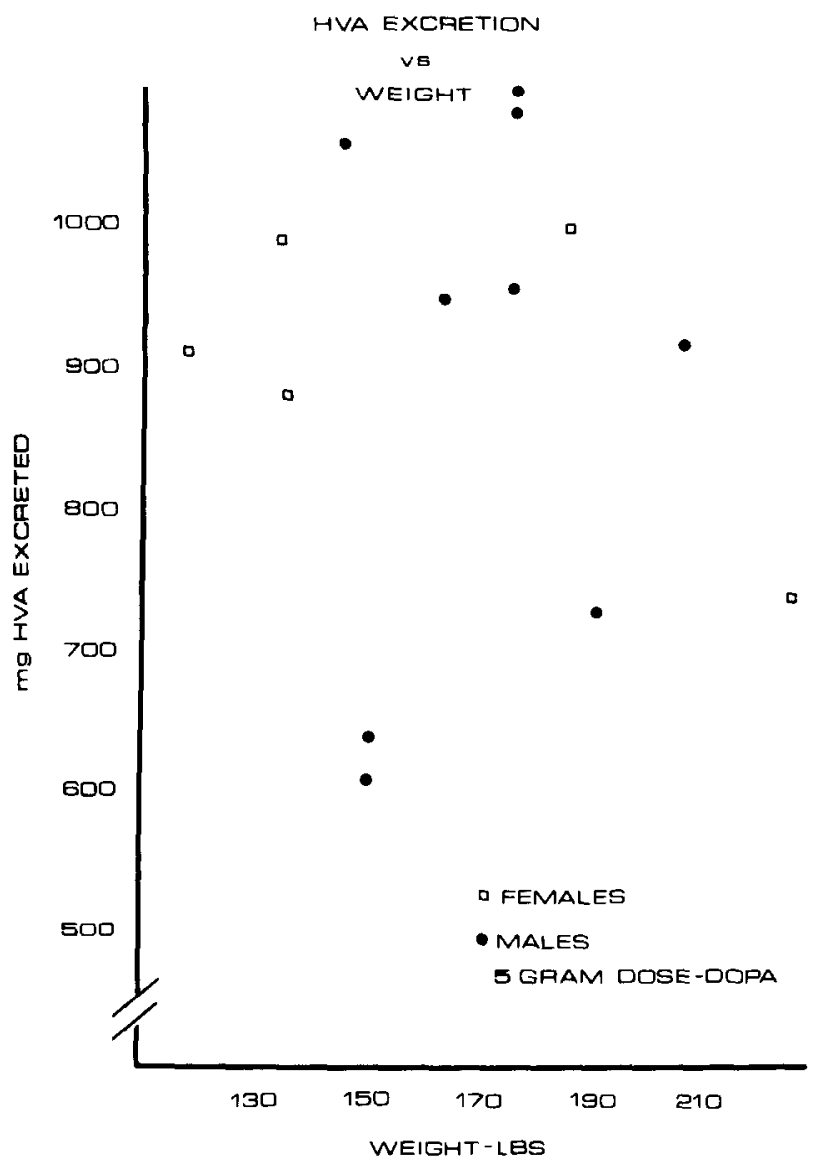

Fig. 3. Twenty-four-hour urinary excretion of homovanillic acid $v s$. weight of patients on 5 grams daily dose of L-dopa.

DISCUSSION

A defect in the handling of basal ganglia dopamine by the parkinsonian patient has been amply documented and is in fact reflected in cerebrospinal fluid HVA levels $\mathbf{~}^{\mathbf{1 , 2}}$. However the total amount of dopamine in the involved areas represents such a small percentage of the total dopamine metabolism of the body that the alterations remain undetectable in urinary excretion studies. Parallel findings were recently reported by Gruendig and Gerstenbrand ${ }^{14}$ who discovered abnormalities in specific amino acid and transaminase levels in the cerebrospinal fluid of parkinsonian patients which were not demonstrable in blood serum obtained simultaneously from the same patients.

It is then correspondingly surprising to find VMA excretions increased markedly in the parkinsonian patients. On the other hand it is the third tyrosine catabolite 
showing sufficiently extensive aberrations in metabolism to be documentable by urinary analysis. The excretion of methoxytyramine ${ }^{15}$ and of $p$-hydroxyphenylpyruvic acid $^{16}$ were previously reported as showing marked changes in the parkinsonian patient.

As a matter of fact it was this increase in p-hydroxyphenylpyruvic acid which prompted the HA work reported in the current manuscript, since p-hydroxyphenylpyruvic is the immediate precursor of HA. From the lack of HA in the parkinsonian urine it is evident that conversion of HA to fumarylacetoacetate is not affected by the disease. It also supports the hypothesis raised in the earlier paper that the elevation of p-hydroxyphenylpyruvic acid is due to increases in liver tyrosine transaminase levels rather than to a block in the metabolism of the keto acid. Regulation of hepatic tyrosine transaminase activity in vivo by norepinephrine and pyridoxal phosphate has been demonstrated ${ }^{17,18}$.

The significance of the elevated VMA levels of the parkinsonian patient is difficult to asses. In concert with the above arguments it is probably a symptom of systemic involvement in the disease rather than a finding which can be dircetly attributed to the altered central nervous system metabolism of dopamine. Goodall and Alton ${ }^{19}$ infused small doses (ca. I mg) of radioactively labelled dopamine into three parkinsonian patients and six nomal subjects and monitored ${ }^{11} \mathrm{C}$ excretions. They were most impressed by a decrease in the percent of the dose excreted as free norepinephrine. However a scrutiny of the percentage of the ${ }^{14} \mathrm{C}$ excreted as VMA plus its precursor dihydroxymandelic acid supports the concept of an increased norepinephrine (and/or epinephrine) metabolism. Finally, Tissot ${ }^{15}$ reported 24 -h urinary VMA excretion values for five parkinson patients $(6.02 \neq 4.03 \mathrm{mg})$ and 20 normal subjects $(3.56 \pm$ I.I $\mathrm{mg}$ ) which closely parallel our own data.

Under the influence of orally administered L-dopa both urinary HVA and VMA rose. Free HVA rather consistently accounted for $18-20 \%$ of the administered dose of L-dopa. While VMA rose with the administered dose the percent of the dose excreted in this form fell progressively from $0.74 \%$ for a $2-\mathrm{g} /$ day to $0.38 \%$ for a $7.5-\mathrm{g} / \mathrm{day}$ dose. Also there is the striking direct correlation between body weight and the amount of administered L-dopa excreted as VMA, a relationship not detectable for HVA. These relationships appear to emphasize that the catabolite VMA cannot be obtained except through either of the physiologically active compounds norepinephrine and epinephrine.

As described in the earlier paper ${ }^{2}$ some correlations exist between the clinical status of parkinsonian patients and the measurement of some of the dopa catabolites in cerebrospinal fluid. Urines from the Group I patients (see Table II) were drawn from the same population as that used for the cerebrospinal fluid studies. In the case of the urinary catabolites of L-dopa, free HVA and free VMA, no correlation was obtained between their excretion and the clinical status or response to L-dopa of the patients.

\section{ACKNOWLEDGEMENT}

Studies were supported in part by a grant from Hoffmann LaRoche and by MSR \& E Research Grant 53-69-70, Wayne County General Hospital. 


\section{REFERENCES}

I N. S. Sharpless and D. S. McCann, Clin. Chim. Acta, 3I (I97I) I 55.

2 N. S. Sharpless, A. D. ERICSSON AND D. S. MCCANN, Neurology, 2 I (1971) $54^{\circ}$.

3 T. L. SaTo, J. Lab. Clin. Med., 66 (1965) 5 I7.

4 R. E. Stoner and B. B. Blivaiss, Clin. Chem., i I (1965) 833.

5 J. E. Seegmiller, V. G. Zannoni, L. Laster and B. N. LaDu, J. Biol. Chem., 236 (I961) 774.

6 D. Wybenga and V. J. Pileggi, Clin. Chim. Acta, i6 (1966) I 47.

7 G. M. Tyce and M. D. Muenter, in A. Barbeau and F. H. McDowell (Eds.), L-Dopa and Parkinsonism, F. A. Davis Company, Philadelphia, Pa., I970, p. 244.

8 G. C. Cotzias, New Engl. J. Med., 278 (Ig68) 630.

9 M. J. Arras and G. W. H. Bailey, New Engl. J. Med., 278 (1968) 280 ,

io S. Wilk, S. Gitlow, M. Mendlowitz, M. J. Franklin, H. E. Carr and D. D. Clarke, Anal. Biochem., 13 (I965) 544 .

i i C. M. Williams and M. Greer, Clin. Chim. Acta, i i (r965) 495.

I 2 Z. Kahane, J. H. Mowat and P. Vestergand, Clin. Chim. Acta, 26 (1969) 307.

i 3 A. D. Ericsson, N. S. Sharpless, E. Honos, W. E. Szpunar and D. S. McCann, in A. BarBEAU And F. H. McDowell (Eds.), L-dopa and Parkinsonism, F. A. Davis Company, Philadelphia, Pa., I97o, p. 217.

I4 Gruendig and Gerstenbrand, Wien. Klin. Wochschr., 82 (I970) 3 I I.

I5 R. Tissot, in A. Barbeau and F. H. McDowell (Eds.), L-Dopa and Parkinsonism, F. A. Davis Company, Philadelphia, Pa., I970, p. 80.

t6 F. Honos, A. D. Ericsson and D. S. McCann, Life Sci., 9 (1970) 159.

I 7 I. B. Black and J. Axelrod, Proc. Natl. Acad. Sci. U.S., 59 (1968) I23I.

I8 I. B. Black, J. Pharmacol. Exp. Therap., I 74 (1970) 283.

I9 McC. Goodall and H. Alton, Biochem. Pharmacol., i 7 (I968) 905.

Clin. Chim. Acta, 35 (I97I) 209-2I7 